\title{
Microgeographic variation in locomotor traits among lizards in a human-built environment
}

Colin Donihue

Microgeographic variation in fitness-relevant traits may be more common than previously appreciated. The fitness of many vertebrates is directly related to their locomotor capacity, a whole-organism trait integrating behavior, morphology, and physiology. Because locomotion is inextricably related to context, I hypothesized that it might vary with habitat structure in a wide-ranging lizard, Podarcis erhardii, found in the Greek Cyclade Islands. I compared lizard populations living on human-built rock walls, a novel habitat with complex vertical structure, with nearby lizard populations that are naive to human-built infrastructure and live in flat, loose-substrate habitat. I tested for differences in morphology, behavior, and performance. Lizards from built sites were larger and had significantly (and relatively) longer forelimbs and hindlimbs. The differences in hindlimb morphology were especially pronounced for distal components - the foot and longest toe.

These morphologies facilitated a significant behavioral shift in jumping propensity across a rocky experimental substrate. I found no difference in maximum velocity between these populations, however females originating from wall sites potentially accelerated faster over the rocky experimental substrate. The variation between these closely neighboring populations suggests that the lizards inhabiting walls have experienced a suite of trait changes enabling them to take advantage of the novel habitat structure created by humans. 


\title{
Microgeographic variation in locomotor traits among lizards in a human-built environment
}

\author{
Colin M. Donihue ${ }^{1 *}$
}

${ }^{1}$ Yale University, School of Forestry and Environmental Studies, New Haven CT, USA

*Correspondence: colin.donihue@yale.edu

\section{Abstract:}

Microgeographic variation in fitness-relevant traits may be more common than previously appreciated. The fitness of many vertebrates is directly related to their locomotor capacity, a whole-organism trait integrating behavior, morphology, and physiology. Because locomotion is inextricably related to context, I hypothesized that it might vary with habitat structure in a wide-ranging lizard, Podarcis erhardii, found in the Greek Cyclade Islands. I compared lizard populations living on human-built rock walls, a novel habitat with complex vertical structure, with nearby lizard populations that are naive to human-built infrastructure and live in flat, loose-substrate habitat. I tested for differences in morphology, behavior, and performance. Lizards from built sites were larger and had significantly (and relatively) longer forelimbs and hindlimbs. The differences in hindlimb morphology were especially pronounced for distal components - the foot and longest toe. These morphologies facilitated a significant behavioral shift in jumping propensity across a rocky experimental substrate. I found no difference in maximum velocity between these populations, however females originating from wall sites potentially accelerated faster over the rocky experimental substrate. The variation between these closely neighboring populations suggests that the lizards inhabiting walls have experienced a suite of trait changes enabling them to take advantage of the novel habitat structure created by humans.

\section{Keywords:}


27 locomotion, morphometrics, context-dependence, local adaptation, Podarcis erhardii

\section{Introduction:}

Animal locomotion integrates a suite of morphological, behavioral, and physiological

30

31

32 attributes and impacts an individual's fitness (Irschick and Garland 2001, Calsbeek and Irschick 2007, Irschick et al. 2008). Furthermore, locomotor behavior and performance is of necessity closely tied to an individual's immediate ecological setting (Losos 1990, Toro et al. 2004, Kohlsdorf and Navas 2007). While traits associated with locomotion are often considered typological for a species, emerging evidence suggests that microgeographic variability in ecological context can result in considerably more intraspecific variation in fitness-relevant traits than previously appreciated (Richardson et al. 2014).

Other studies have demonstrated that the substrate and structure of a habitat are consistently related to a lizard species' behavior, morphology, and performance (Vanhooydonck and Van Damme 2003, Calsbeek and Irschick 2007 Kohlsdorf and Navas 2007, Losos 2011). Lizards in more complex habitats tend to more often jump from branch-to-branch or rock-to-rock (Kohlsdorf and Navas 2007, Harrison et al. 2015). Additionally, jumping performance in lizards is often associated with longer hind limbs, particularly in the distal segments between the ankle and the tip of the longest toe (Moermond 1979, Losos 1990, Toro et al. 2004). Laboratory tests of lizard locomotion typically employ a single experimental substrate. Moreover, the types of substrates used may (e.g. sand) or may not (e.g. cork or sandpaper) reflect naturally occurring substrates that have given rise to different adaptations for locomotion.

7 Comparing lizard locomotion across multiple substrates is increasingly the focus of new studies (Tulli et al. 2012, Vanhooydonck et al. 2015), but these studies have yet to investigate performance of conspecifics living in different habitats and test predictions of associated 
50 morphological and behavioral differences according to those habitats.

51 Humans are ecosystem engineers, creating novel habitat structure across landscapes and

52 exerting strong adaptive pressure on the organisms in those landscapes (Jones et al. 1994,

53 Donihue and Lambert 2014). In the Greek islands, stone walls and terraces crisscross the

54 landscape, and the eponymous Aegean Wall Lizard, Podarcis erhardii, can readily be found

55 throughout (Valakos et al. 2008). However, P. erhardii, can also commonly be found dashing

56 between bushes in nearby wall-less habitats with sand or loose-soil substrates. Podarcis erhardii

57 living on stone walls experience a more structurally complex habitat than their conspecifics in

58 non-wall habitats (Fig. 1). Based on other research showing that lizard traits change to

59 accommodate new demands for locomotor performance in rocky habitats (Goodman 2007,

60 Kohlsdorf and Navas 2007, Revell et al. 2007), I hypothesized that human alteration of the

61 landscape should affect behavioral and morphological traits associated with locomotion. I tested

62 for differences in jumping behavior, limb morphology, and sprinting performance between

63 lizards living in areas with walls and areas without walls. The research demonstrates that human

64 alteration of the environment can result in considerable microgeographic variation in important

65 whole-organism traits such as locomotion.

\section{Methods:}

I collected 324 adult $P$. erhardii from $10,50 \mathrm{~m}$ by $50 \mathrm{~m}$ sites within $15 \mathrm{~km}$ of each other on Naxos, a large island in the Greek Cyclade Islands. Five sites had stone walls, the other five were characterized by sandy substrate with interspersed Juniperus oxycedrus shrubs or a loose

70 jumble of soil and Mediterranean phrygana (Fig. 1). All sites were selected for having a high

71 density of lizards, and non-wall sites for being more than $200 \mathrm{~m}$ from the nearest built stone

72 structure. While $P$. erhardii home range has not been investigated, sister species have reported 
73 home ranges no larger than $120 \mathrm{~m}^{2}$ (Brown et al. 1995, Swallow et al. 1996) suggesting it is

74 highly unlikely lizards from non-wall sites had originated on walls. For all lizards, I recorded sex

75 and measured snout-to-vent length (SVL), and the length of each segment of the right fore and

76 hind limb using digital calipers (Frankford Arsenal 672060).

77 I constructed two tracks for assessing lizard locomotion. Each track was $50 \mathrm{~cm}$ wide and

$782 \mathrm{~m}$ long, with walls approximately $50 \mathrm{~cm}$ tall, constructed from heavy-duty plastic sheeting.

79 One track had a sandy substrate $(5 \mathrm{~cm}$ depth) reflecting the homefield of the five non-wall lizard

80 populations, and the other was paved with large flagstones (averaging approximately $20 \mathrm{~cm}$ in

81 diameter) from nearby walls. These flagstones were placed so each abutted the next, resulting in

82 haphazard small (1 to $4 \mathrm{~cm}$ ) gaps between uneven rock edges, mimicking the position and

83 spacing of stones on top of local rock walls. The arrangement of rocks did not change through

84 the entirety of the experiment. The track was not heated and conditions were kept consistent for 85 all trials.

86 Before each trial, all lizards were allowed to thermoregulate at will for at least 30 minutes

87 along a temperature gradient radiating from a suspended lamp (sand temperature 45C to 25C).

88 Immediately before running the lizard, I recorded their temperature using a cloacal thermometer

89 (Miller and Webber T6000). The sprinting temperatures selected by males and females between

90 wall and non-wall sites did not significantly differ (Males: wall: 29.7 $\pm 1.2 \mathrm{C}$, non-wall:

$9130.3 \pm 1.9 \mathrm{C}$; Females: wall: $29.3 \pm 1.2 \mathrm{C}$, non-wall: $29.2 \pm 2.2 \mathrm{C})$. Lizards were stationary in the same

92 start position at the beginning of each trial. Each sprint was recorded with a video camera (Sony

93 HDRPJ260V; 1920 x 1080 px; $50 \mathrm{~Hz}$ ) suspended directly over the track using a tripod. The

94 camera's field of view encompassed the first $1.5 \mathrm{~m}$ of track and had a full dorsal perspective of 
95 the running lizard. As motivation impacts sprint speed performance (Losos et al. 2002, Irschick

96 et al. 2005), if the lizard did not seemingly run maximally I discarded their trial during analysis.

97 I calculated the position of the lizard frame-by-frame relative to a tape measure in the

98 field of view using a custom-built JavaScript program (code: https://github.com/bkazez/savra).

99 To calculate velocity and acceleration, I fit a quintic spline to the position data (Walker 1998)

100 with the SPAPI function in MatLab (MathWorks Inc., 2014). This spline function was then

101 differentiated such that the maximum of the first derivative yielded maximum velocity, the

102 second derivative, maximum acceleration. Finally, I watched each stone-substrate trial and

103 counted the number of times the lizards jumped (body and all limbs simultaneously in the air)

104 from rock to rock. The Yale IACUC office approved all experiments involving animals (permit:

105 2013-11548). All work was conducted with permission from the Greek Ministry of Environment,

106 Energy, and Climate Change (Permit 11665/1669).

\section{Statistical analyses}

108 To test for differences in morphology between populations I used linear mixed effects

109 models, evaluated using the LME command within the NLME (v3.1-121; 2015) package in R

$110(\mathrm{v} 3.1 .2 ; 2014)$. As the morphometric and performance traits were not normally distributed, each

111 was $\log _{10}$ transformed before analysis. Each morphometric was treated as a response variable

112 with presence or absence of wall as fixed effects and with site of origin as a random effect. I

113 tested for relative morphological differences by adding SVL as a covariate. To test for

114 differences in performance response variables - maximum velocity and acceleration over each

115 substrate - I again used wall presence or absence as a fixed effect and site of origin as a random

116 effect with sprint temperature as an additional random effect. Finally, to determine whether there

117 was a difference in propensity to jump between the wall and non-wall populations, I used the 
118 count of jumps across the rocky experimental substrate as a fixed effect and included

119 temperature as a random effect. A Shapiro-Wilk test determined that jump counts were not

120 normally distributed ( $\mathrm{W}=0.9435, \mathrm{P}<0.0001$ ), and so I $\log _{10}$ transformed the jump counts for all

121 analyses. Whenever body size or temperature was used in a model, they were standardized to

122 have a mean of zero so as to make the estimates of each response variable directly interpretable

123 (standardized value $=$ initial value - global mean value). In all cases, males and females were

124 analyzed independently to reduce interactions in the models. Finally, I used a type II ANOVA

125 (CAR package, v2.0-25) to calculate Wald chi-square values for the model fixed effects

126 and assign $p$-values appropriate for the unbalanced design (Langsrud 2003). Figures were made

127 in JMP (v11.2.0. SAS Institute Inc 2013.).

128 Results:

129 For clarity, all test statistics are related in the referenced tables. In-text, I instead present

130 the average trait value, plus and minus the standard error. Lizards, both males and females, from

131 wall sites had larger SVLs than lizards at non-wall sites (males: wall: $62.42 \pm 0.62 \mathrm{~mm}$, non-wall

$13258.13 \pm 0.44 \mathrm{~mm}$; females: wall: $59.23 \pm 0.74 \mathrm{~mm}$, non-wall: $55.02 \pm 0.59 \mathrm{~mm}$; Fig. 1; Table 1).

133 This pattern was consistent across both sexes for multiple limb measurements (Fig. 1). In

134 particular, the distal portions of the hindlimbs - the length between the ankle joint and the tip of

135 the longest toe, and the longest toe itself - were relatively (standardized by SVL) longer among

136 wall populations (Table 1). All together, lizards living on walls had proportionally longer hind

137 limbs than lizards in non-wall habitats (Fig. 2a, Table 1).

138 I found no difference in maximum velocity among lizards from either habitat of origin

139 across either experimental substrate (male maximum velocity on rock: wall: $1.99 \pm 0.45 \mathrm{~m} / \mathrm{s}$, non-

140 wall $1.98 \pm 0.6 \mathrm{~m} / \mathrm{s}$; female maximum velocity on rock: wall: $1.83 \pm 0.44 \mathrm{~m} / \mathrm{s}$, non-wall 
$1411.76 \pm 0.31 \mathrm{~m} / \mathrm{s}$; male maximum velocity on sand: wall: $1.98 \pm 0.6 \mathrm{~m} / \mathrm{s}$, non-wall: $1.82 \pm 0.42 \mathrm{~m} / \mathrm{s}$;

142 female maximum velocity on sand: wall: $1.73 \pm 0.47 \mathrm{~m} / \mathrm{s}$, non-wall $1.67 \pm 0.34 \mathrm{~m} / \mathrm{s}$; Table 2 ). While

143 I found no difference in either population's acceleration capacity over sand (see Table 2), I found

144 that females from wall sites accelerated over the rocky experimental substrate faster than lizards

145 from non-wall sites (Fig 2b, Table 2).

146 In contrast to other studies, I found that individual SVL was not a significant predictor of

147 maximum velocity or acceleration across either substrate for either sex (Supplemental Table 1).

148 Similarly, hindlimb length and the length of the longest toe did not significantly explain variation

149 in sprinting performance (Supplemental Table 1).

150 Both males and females from wall populations exhibited a strong behavioral shift: the

151 lizards accustomed to walls consistently traversed the rocky experimental substrate by jumping 152 rock-to-rock (see supplemental video files 1 and 2). Non-wall lizards jumped significantly fewer

153 times crossing the same experimental track (males: wall: $3.4 \pm 1.2$ jumps, non-wall: $2.5 \pm 1.2$

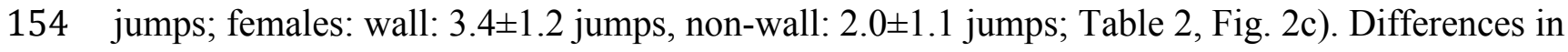

155 jumping propensity were not explained by SVL (Table 3), however jump counts were

156 significantly informed by the length of the distal components of the hind limbs (male longest toe:

$157 p=0.0181$; female longest toe: $p=0.0108$; Table 3 ).

158 Discussion:

159 I found consistent differences between close-proximity populations of $P$. erhardii

160 inhabiting different habitat-structure contexts. Lizards originating on sites with walls were larger

161 than lizards from non-wall sites. Furthermore, the absolute length of each component of the hind

162 limbs, and the relative length of the hindlimb as a whole was proportionally larger among wall 
163 populations of both sexes (Fig. 2a). The difference in relative hindlimb length was driven by

164 proportional differences in the foot and longest toe of wall-inhabiting lizards (Table 1).

165 Morphological differences between lizard populations sometimes result in local, habitat-

166 specific performance advantages (e.g. limb length determining motility across branches of

167 different diameters in Anolis; Calsbeek and Irschick 2007, Losos 2011). Long limbs in Lacertids

168 are in some species an adaptation for fast sprints over loose substrates (Bauwens et al. 1995,

169 Bonine and Garland Jr. 1999). However, I found no inter-population differences in sprinting

170 ability across sand. Alternatively, long hind limbs are also associated with jumping capacity and

171 propensity (Moermond 1979, Losos 1990, Toro et al. 2004), particularly in rocky habitats

172 (Goodman 2007, Kohlsdorf and Navas 2007, Revell et al. 2007). Indeed, I found that lizards

173 from wall sites (with longest hind limbs) jump 1.5 times more often than non-wall populations

174 on the same experimental track (Fig. 2c; supplemental video files 1 and 2). While there was no

175 difference in the maximum sprint velocity of either population across either substrate, I found

176 that females from rock wall populations accelerated more quickly than those from the non-wall

177 habitats over the rocky experimental substrate (Fig. 2b).

178 Motivation will considerably affect measurements of an animal's performance in

179 laboratory conditions (Losos et al. 2002, Irschick et al. 2005). For that reason, many trials on

180 relatively fewer individuals may provide clearer insights into maximal ability; however, even

181 these results should be interpreted with caution (Losos et al. 2002, Irschick et al. 2005). Due to

182 logistical constraints, repeated trials were not possible for this study, and accordingly the high

183 variation in performance obscured the trends predicted for the observed morphological

184 differences between populations. Additionally, others have demonstrated that slow video frame

185 rates are prone to errors in estimating acceleration of fast-moving animals (Walker 1998). A 50 
$186 \mathrm{~Hz}$ camera was the maximum speed available for this field study, and, although my calculated

187 values (Table 4) are commensurate with published values for closely related species

188 (Vanhooydonck et al. 2015), further work with high-speed cameras (exceeding $250 \mathrm{~Hz}$ ) and

189 repeated trials will be necessary to show whether and how these observed morphological

190 differences translate to performance differences.

191 Few studies investigate relative lizard locomotion capacity over multiple experimental

192 substrates (Vanhooydonck et al. 2015). Studies that have, did not find that species racing on an

193 experimental substrate similar to their characteristic natural habitat necessarily performed better

194 (Tulli et al. 2012, Vanhooydonck et al. 2015). This study suggests one potential explanation: the

195 intraspecific differences observed here are commensurate with some published interspecific

196 comparisons (Tulli et al. 2012, Vanhooydonck et al. 2015), meaning that variation among source

197 populations could change the interpretation of interspecific comparisons. This study

198 demonstrates that locomotor behavior and performance is contingent on the structure and

199 ecology of source populations and not necessarily typological for a species.

200 Intraspecific context-dependence in locomotion morphometrics have been demonstrated

201 between physically isolated populations (e.g. island vs mainland; Van Damme et al. 1998), and

202 populations inhabiting dramatically different natural contexts (e.g. Des Roches et al. 2014).

203 Coordinated intraspecific changes in locomotion behavior, morphology, and performance are

204 strong indications that selection acts holistically on these traits across ecological contexts (Miles

205 et al. 2001, Calsbeek and Irschick 2007, Gifford et al. 2008). The differences related here in

206 lizard morphology and jumping behavior over small spatial scales are noteworthy, and

207 demonstrate the significant potential effect of anthropogenic microhabitat alteration on an

208 important whole-organism trait, locomotion. 


\section{Acknowledgements:}

211 Thanks go to P. Pafilis and J. Foufopoulos for logistical aid in-country; K. Culhane, Z. Miller, 212 and A. Mossman for help in the field; B. Kazez and B. Redding for video analysis assistance; 213 and A. Herrel, M. Lambert, O. Schmitz, and D. Skelly for manuscript comments. 


\section{References:}

216 Bauwens D, Garland Jr. T, Castilla AM, van Damme R. 1995. Evolution of sprint speed in

217 lacertid lizards: morphological, physiological and behavioral covariation. Evolution 49, 848$218 \quad 863$.

219 Bonine KE, Garland Jr. T. 1999. Sprint performance of phrynosomatid lizards, measured on a 220 high-speed treadmill correlates with hindlimb length. Journal of Zoology 248, 255-265. (doi: 10.1111/j.1469-7998.1999.tb01201.x)

222 Calsbeek R, Irschick DJ. 2007. The quick and the dead: Correlational selection on morphology, 223 performance, and habitat use in island lizards. Evolution 61, 2493-2503.

224 Des Roches S, Torresdal J, Morgan TW, Harmon LJ, Rosenblum EB. 2014. Beyond black and 225 white: divergent behavior and performance in three rapidly evolving lizard species at White Sands. Biological Journal of the Linnaean Society 111, 169-182. (doi: 10.1111/bij.12165)

227 Donihue CM, Lambert MR. 2014. Adaptive evolution in urban ecosystems. AMBIO 44, 194203. (doi: 10.1007/s13280-014-0547-2)

229 Gifford ME, Herrel A, Mahler DL. 2008. The evolution of locomotor morphology, performance, 230 and anti-predator behavior among populations of Leiocephalus lizards from the Dominican 231 Republic. Biological Journal of the Linnean Society 93, 445-456.

232 Goodman BA. 2007. Divergent morphologies, performance, and escape behavior in two tropical 233 rock-using lizards (Reptilia: Scincidae). Biological Journal of the Linnean Society 91, 85-98.

234 Harrison AS, Revell LJ, Losos JB. 2015. Correlated evolution of microhabitat, morphology, and 235 behavior in West Indian Anolis lizards: a test of the habitat matrix model. Behaviour 152, $236 \quad 1187-1207$.

237 Irschick DJ, Garland TJ. 2001. Integrating function and ecology in studies of adaptation: 
investigations of locomotor capacity as a model system. Annual Review of Ecology, Evolution, and Systematics 32, 367-396.

240 Irschick DJ, Herrel A, Vanhooydonck B, Huyghe K, Van Damme R. 2005. Locomotor compensation creates a mismatch between laboratory and field estimates of escape speed in lizards: A cautionary tale for performance-to-fitness studies. Evolution 59, 1579-1587.

243 Irschick DJ, Meyers JJ, Husak JF, Le Galliard J. 2008. How does selection operate on whole244 organism functional performance capacities? A review and synthesis. Evolutionary Ecology $245 \quad$ Research 10, 177-196.

246 Jones CG, Lawton JH, Shachak M. 1994. Organisms as ecosystem engineers. Oikos 69, 373-386.

247 Kohlsdorf T, Navas CA. 2007. Evolution of jumping capacity in Tropidurinae lizards: does

248 habitat complexity influence obstacle-crossing ability? Biological Journal of the Linnean

249 Society 91, 393-402.

250 Langsrud, Øyvind. 2003. ANOVA for unbalanced data: Use Type II instead of Type III sums of $251 \quad$ squares. Statistics and Computing 13, 163-167.

252 Losos JB. 1990. The evolution of form and function: Morphology and locomotor performance in 253 West Indian Anolis lizards. Evolution 44, 1189-1203.

254 Losos JB. 2011. Lizards in an evolutionary tree. Ecology and adaptive radiation of Anoles.

255 Berkeley, CA: University of California Press.

256 Losos JB, Creer DA, Schulte II JA. 2002. Cautionary comments on the measurement of 257 maximum locomotor capabilities. Journal of Zoology London 258, 57-61.

258 Miles DB, Snell HL, Snell HM. 2001. Intrapopulation variation in endurance of Galápagos lava 259 lizards (Microlophus albemarlensis): evidence for an interaction between natural and sexual 260 selection. Evolutionary Ecology Research 3, 795-804. 
261 Moermond TC. 1979. Habitat constraints on the behavior, morphology, and community structure 262 of Anolis lizards. Ecology 60, 152-164.

263 Revell LJ, Johnson MA, Schulte II JA, Kolbe JJ, Losos JB. 2007. A phylogenetic test for 264 adaptive convergence in rock-dwelling lizards. Evolution 61, 2898-2912.

265 Richardson JL, Urban MC, Bolnick DI, Skelly DK. 2014. Microgeographic adaptation and the 266 spatial scale of evolution. Trends in Ecology and Evolution 29, 165-176. (doi:

267 doi:10.1016/j.tree.2014.01.002)

268 Toro E, Herrel A, Irschick D. 2004. The evolution of jumping performance in Caribbean Anolis 269 lizards: solutions to biomechanical trade-offs. American Naturalist 163, 844-856.

270 Tulli MJ, Abdala V, Cruz FB. 2012. Effects of different substrates on the sprint performance of 271 lizards. Journal of Experimental Biology 215, 774-784. (doi: 10.1242/jeb.065490)

272 Valakos E, Pafilis P, Sotiropoulos K, Lymberakis P, Maragou P, Foufopoulos J. 2008. The 273 Amphibians and Reptiles of Greece. Frankfurt Germany: Chimaira.

274 Van Damme R, Aerts P, Vanhooydonck B. 1998. Variation in morphology, gait characteristics 275 and speed of locomotion in two populations of lizards. Biological Journal of the Linnaean 276 Society 63, 409-427. (doi: 10.1111/j.1095-8312.1998.tb01526.x)

277 Van Damme R, Vanhooydonck B. 2001. Origins of interspecific variation in lizard sprint $278 \quad$ capacity. Functional Ecology 15, 186-202.

279 Vanhooydonck B, Measey J, Edwards S, Makhubo B, Tolley KA, Herrel A. 2015. The effects of 280 substratum on locomotor performance in lacertid lizards. Biological Journal of the Linnaean $281 \quad$ Society (doi: 10.1111/bij.12542) 
282 Vanhooydonck B, Van Damme R. 2003. Relationships between locomotor performance,

283 microhabitat use and antipredator behavior in lacertid lizards. Functional Ecology 17, 160-

284 169. (doi: 10.1046/j.1365-2435.2003.00716.x)

285 Walker JA. 1998. Estimating velocities and accelerations of animal locomotion: a simulation

286 experiment comparing numerical differentiation algorithms. Journal of Experimental Biology

$287 \quad 201,981-995$.

288

289 
290 Figure 1: The island of Naxos in the Greek Cyclades and representative pictures of the sites with

291 and without walls. I found significant differences in the body size (SVL) and hindlimb

292 morphology of males (bold blue) and females (light red) from wall (top) and non-wall (bottom)

293 sites. Total limb length was calculated from the sum of component parts, see Table 1 for

294 segment-by-segment comparisons between the populations. Mean and standard error are

295 presented for each measurement along with the p-value of the size-corrected LME model (see

296 Table 1).

297

298 Figure 2: Lizards from wall sites had proportionally longer hindlimbs, relative to SVL (a). These

299 longer hindlimbs corresponded to significantly faster accelerations among females over a rocky

300 experimental substrate (b), and to significantly increased jumping propensity for both males and

301 females (c). Shaded regions in (a) reflect 95\% confidence intervals and standard error bars have

302 been added for (b) and (c). All comparisons with (*) are significant $\mathrm{p}<0.05$.

303

304 


\section{Figure 1:}

306
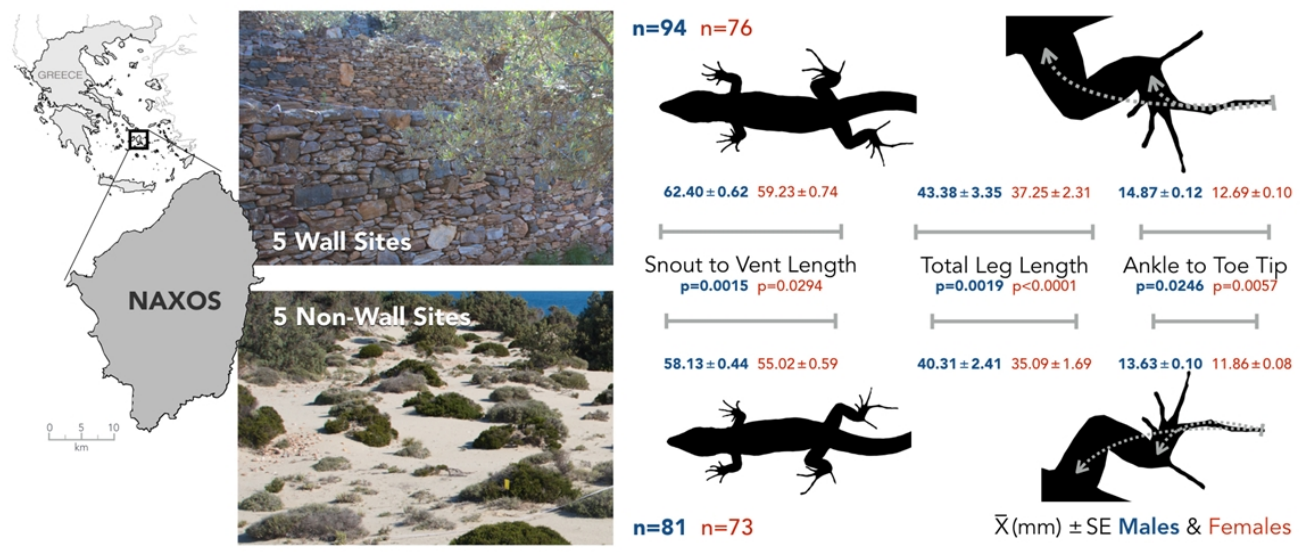
307 Figure 2:

308
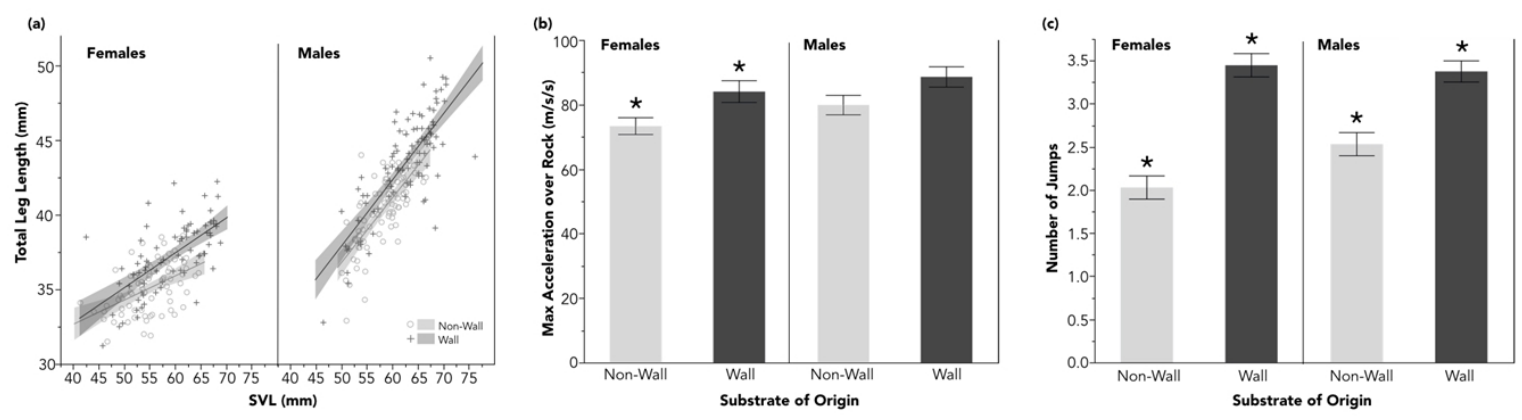
Table 1: Results of the linear mixed effects models comparing morphological measurements between wall and non-wall lizard populations. After SVL was shown to differ between sites, relative differences in morphology, that is, morphology standardized by SVL was tested. All morphometrics were $\log 10$ transformed to meet assumptions of normality. A $\left({ }^{*}\right)$ denotes significance at the $\mathrm{p}<0.05$ level.

\begin{tabular}{|c|c|c|c|c|c|c|c|c|c|}
\hline \multirow[b]{3}{*}{ Morphometric: } & \multicolumn{9}{|c|}{$\sim$ Wall | Site } \\
\hline & \multicolumn{4}{|c|}{ Males } & \multicolumn{5}{|c|}{ Females } \\
\hline & $\mathrm{N}$ & $\mathrm{X}^{2}$ & $\mathrm{DF}$ & $p$ & $\mathrm{~N}$ & $\mathrm{X}^{2}$ & $\mathrm{DF}$ & $p$ & \\
\hline SVL & 175 & 9.017 & 1 & $0.0027 *$ & 149 & 4.343 & 1 & 0.0372 & $*$ \\
\hline \multicolumn{3}{|l|}{ Model: } & \multicolumn{5}{|c|}{$\sim$ Wall + SVL | Site } & & \\
\hline Total arm length & 175 & 0.010 & 1 & 0.9213 & 149 & 3.849 & 1 & 0.0498 & * \\
\hline Hip to knee & 175 & 0.473 & 1 & 0.4918 & 149 & 1.018 & 1 & 0.3130 & \\
\hline Knee to ankle & 175 & 0.066 & 1 & 0.7974 & 149 & 3.512 & 1 & 0.0609 & \\
\hline Ankle to tip of toe & 175 & 5.226 & 1 & $0.0223 *$ & 149 & 9.016 & 1 & 0.0027 & * \\
\hline Longest toe & 175 & 5.774 & 1 & $0.0163 *$ & 149 & 19.701 & 1 & $<0.0001$ & $*$ \\
\hline Total leg length & 175 & 9.717 & 1 & $0.0018 *$ & 149 & 15.446 & 1 & $<0.0001$ & * \\
\hline
\end{tabular}


Table 2: Linear mixed effects models comparing performance and behavior between wall and non-wall lizard populations. All performance and behavior metrics were Log10 transformed to meet assumptions of normality. A $\left(^{*}\right)$ denotes significance at the $\mathrm{p}<0.05$ level.

\begin{tabular}{|lcccc|ccccc|}
\hline \multicolumn{1}{|c}{ Model: } & \multicolumn{6}{c|}{$\sim$ Wall + SVL | Site + SprintTemp } \\
& \multicolumn{5}{c|}{ Males } & \multicolumn{5}{c|}{ Females } \\
Performance metric: & $\mathrm{N}$ & $\mathrm{X}^{2}$ & $\mathrm{DF}$ & $p$ & $\mathrm{~N}$ & $\mathrm{X}^{2}$ & $\mathrm{DF}$ & $p$ \\
Max velocity rock & 171 & 0.966 & 1 & 0.3256 & 143 & 1.577 & 1 & 0.2092 \\
Max acceleration rock & 170 & 1.587 & 1 & 0.2078 & 143 & 7.024 & 1 & 0.0080 \\
Max velocity sand & 166 & 0.070 & 1 & 0.7915 & 142 & 0.389 & 1 & 0.5329 \\
Max acceleration sand & 165 & 0.203 & 1 & 0.6526 & 141 & 0.128 & 1 & 0.7202 \\
Jumps & 172 & 3.810 & 1 & $0.0481 *$ & 145 & 6.643 & 1 & $0.0099 *$ \\
\hline
\end{tabular}


Table 3: Results of regressions between three morphological variables and the count of jumps across the rocky substrate. All variables were $\log 10$ transformed to fit the assumption of normality. A $(*)$ denotes significance at the $\mathrm{p}<0.05$ level.

\begin{tabular}{|lrcc|c|}
\hline & & \multicolumn{2}{c|}{ Jumps } \\
SVL & $p=$ & 0.2573 & 0.1557 \\
& $\mathrm{R}^{2} \mathrm{Adj}=$ & 0.0017 & 0.0073 \\
Length of longest toe & $p=$ & $0.0181 *$ & 0.0108 \\
& $\mathrm{R}^{2} \mathrm{Adj}=$ & 0.027 & 0.0389 \\
Total hindlimb length & $p=$ & 0.1182 & 0.0031 \\
& $\mathrm{R}^{2} \mathrm{Adj}=$ & 0.0085 & 0.0543 \\
\hline
\end{tabular}


Table 4: Average and standard deviation of the performance of lizards from wall and non-wall sites.

\begin{tabular}{|c|c|c|c|c|c|c|c|c|}
\hline & \multicolumn{4}{|c|}{ Males } & \multicolumn{4}{|c|}{ Females } \\
\hline & \multicolumn{2}{|c|}{ Wall } & \multicolumn{2}{|c|}{ No Wall } & \multicolumn{2}{|c|}{ Wall } & \multicolumn{2}{|c|}{ No Wall } \\
\hline & Mean & $\pm \mathrm{SD}$ & Mean & $\pm \mathrm{SD}$ & Mean & $\pm \mathrm{SD}$ & Mean & $\pm \mathrm{SD}$ \\
\hline Velocity Rock (m/s) & 1.99 & 0.45 & 1.91 & 0.47 & 1.83 & 0.44 & 1.76 & 0.31 \\
\hline Acceleration Rock (m/s/s) & 88.57 & 29.87 & 79.84 & 26.89 & 84.05 & 28.67 & 73.32 & 21.78 \\
\hline Velocity Sand (m/s) & 1.98 & 0.60 & 1.82 & 0.42 & 1.73 & 0.47 & 1.67 & 0.34 \\
\hline Acceleration Sand $(\mathrm{m} / \mathrm{s} / \mathbf{s})$ & 87.88 & 38.68 & 81.00 & 30.60 & 77.82 & 29.49 & 77.73 & 35.55 \\
\hline
\end{tabular}

